\title{
Somnolence after Prophylactic Cranial Irradiation in Children with Acute Lymphoblastic Leukaemia
}

\author{
J. E. FREEMAN， P. G. B. JOHNSTON， J. M. VOKE
}

British Medical fournal, 1973, 4, 523-525

\section{Summary}

A transient cerebral disturbance characterized by somnolence of varying degree is described in children after cranial irradiation given as part of central nervous system (C.N.S.) prophylaxis for acute lymphoblastic leukaemia in remission.

Out of 28 such children receiving cranial irradiation as part of the Medical Research Council protocol for C.N.S. prophylaxis $11(39 \%)$ developed pronounced symptoms of somnolence, anorexia, and lethargy some six weeks after the completion of cranial irradiation, and a further $11(39 \%)$ developed these features in mild form. In all cases the symptoms were transient, no focal neurological abnormality was detected, and all children made a spontaneous and complete recovery. E.E.G. studies on five somnolent children showed similar abnormal activity of diffuse and patchy distribution over both hemispheres. Indirect evidence is presented to support the concept that this syndrome represents a transient radiation encephalopathy, analogous to acute transient radiation myelopathy, caused by temporary disturbance of myelip synthesis.

\section{Introduction}

Early in 1973 we noted several cases of pronounced but transient somnolence in children who had completed a course of cranial irradiation about six weeks previously, given as part of central nervous system (C.N.S.) prophylaxis for acute lymphoblastic leukaemia in remission. A prospective study of this syndrome was set up and is still in progress. The purpose of this paper is to report this development and describe the clinical features of postirradiation somnolence in a group of children who all received identical prophylactic cranial irradiation and to discuss its likely pathological basis and significance.

\section{Patients and Treatment}

Between February 1972 and January 197328 children under 15 years of age with newly diagnosed acute lymphoblastic leukremia were treated according to the current Medical Research Council Leukaemia Trial protocol UKALL II. Once haematological remission had been achieved prophylactic C.N.S. irradiation was carried out. The following two regimens of C.N.S. prophylaxis were in use during that period.

Craniospinal Irradiation (7 patients). - Treatment comprised 2,400 rads delivered to the midplane of the cranium and a 2,400-rad depth dose given simultaneously to the spinal meninges in 28 days (20 fractions).

\section{St. Bartholomew's Hospital, London EC1A 7BE}

J. E. FREEMAN, M.R.C.P., F.F.R., Consultant Radiotherapist

Hospital for Sick Children, Great Ormond Street, London W.C.1

P. G. B. JOHNSTON, M.B., M.R.C.P., Leukaemia Research Fellow

J. M. VOKE, M.B., B.S., Leukaemia Research Fellow
Cranial Irradiation and Reduced Spinal Irradiation, with Intrathecal Methotrexate (21 patients).-Treatment comprised 2,400 rads delivered to the midplane of the cranium in 28 days (20 fractions) and four intrathecal injections of methotrexate $\left(10 \mathrm{mg} / \mathrm{m}^{2}\right)$ at weekly intervals during the irradiation; a 1,000 rad depth dose to the spinal meninges was given in the last five days of treatment.

All the parients received 2,400 rads exactly to the midplane of the cranium and there were few deviations from the planned duration of treatment (mean duration 28 days). Treatment was given with a T.E.M. Stabilatron telecobalt unit, and in the youngest children treated ketamine provided general anaesthesia to ensure immobility and accuracy of treatment.

\section{OBSERVATIONS}

For this analysis the notes of all our patients on the UKALL II protocol were reviewed and the parents of all the children interviewed. Of the children who developed symptoms only three were not seen in the clinic at that time. One was under observation at a distant hospital and two had developed and recovered from symptoms between routine clinic visits.

Once the development of somnolence had been recognized all postirradiation symptoms (or their absence) were noted, including the duration and severity of somnolence whenever it occurred. In five children E.E.G. and examination of the cerebrospinal fluid (C.S.F.) were performed during the somnolent phase, and in three E.E.G. was repeated when clinical improvement had occurred.

\section{Somnolence Syndrome}

\section{CLINICAL FEATURES}

Somnolence was the principal symptom and varied from mild drowsiness to prolonged periods of sleep. The more somnolent children slept for as long as 20 hours a day and though easily rousable would remain drowsy while awake. Some would fall asleep at any time during the day, often at inappropriate moments. For example, one child fell asleep in the classroom and had to be taken home still sleeping. Such severe somnolence usually lasted for three to seven days, other symptoms lasting for longer periods. Somnolence was often preceded and followed by several days of anorexia and irritability.

Four children were febrile, with symptoms of upper respiratory infection, and two others developed nausea and mild vomiting.

There was no evidence of raised intracranial pressure or focal neurological abnormality in any affected child and no convulsions occurred. In every child the symptoms subsided spontaneously and completely and normal levels of alertness and physical activity and a normal sleep rhythm were fully re-established.

\section{INCIDENCE}

Altogether 22 children (79\%) developed the syndrome to some degree. In $11(39 \%)$ the symptoms were mild and might well have passed unrecognized, and in the remaining $11(39 \%)$ they 
were severe. The younger children tended to have the mone severe symptoms (fig. 1). There was no significant difference in the incidence of the syndrome between those patients who received only irradiation $(6 / 7 ; 86 \%)$ and those who received irradiation and intrathecal methotrexate $(16 / 21 ; 76 \%)$.

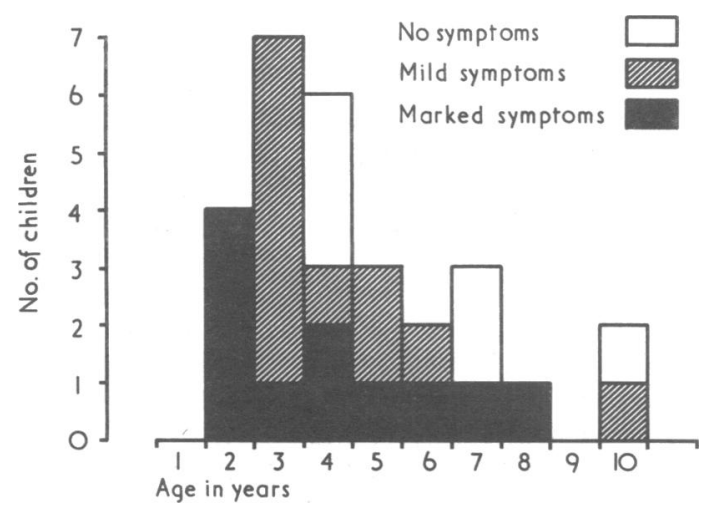

FIG. 1-Severity of somnolence symptoms according to age.

\section{TIME OF ONSET AND DURATION OF SYMPTOMS}

Symptoms appeared between 24 and 56 days (mean 38 days) after the completion of cranial irradiation (fig. 2) and lasted from 10 to 38 days (mean 18.5 days) (table I). The number of children developing symptoms in each successive week after cranial irradiation is shown in fig. 2 , which illustrates a strikingly consistent latent period between the completion of irradiation and the onset of symptoms. Thus 18 of the 22 children $(82 \%)$ first developed symptoms during the fifth and sixth weeks. There was a suggestion that the earlier the symptoms developed the longer they were likely to persist, but this association was not statistically significant (table II).

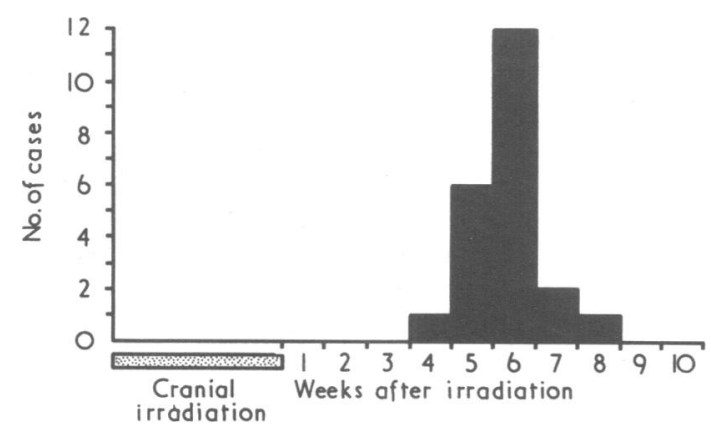

FIG. 2-Time of onset of somnolence syndrome after prophylactic cranial irradiation.

TABLB I-Duration of Symptoms in 22 Children developing Somnolence Syndrome after Prophylactic Cranial Irradiation

\begin{tabular}{|c|c|c|c|c|c|c|}
\hline $\begin{array}{l}\text { Duration in days (mean }=18.5 \text { ) } \\
\text { No. of patients } \ldots \quad \ldots \quad \ldots\end{array}$ & $\because$. & $\because$ & ${ }_{13}^{10-14}$ & $\frac{15-20}{3}$ & $\frac{21-30}{5}$ & $>30$ \\
\hline
\end{tabular}

TABLB II-Time of Onset of Symptoms related to Duration

\begin{tabular}{|c|c|c|c|}
\hline \multicolumn{2}{|c|}{ Time of Onset } & No. of & $\begin{array}{c}\text { Average } \\
\text { Auration }\end{array}$ \\
\hline $\begin{array}{l}\text { 4th and 5th Weeks } \\
\text { 6th Week } \\
\text { 7th and 8th Weeks }\end{array}$ & 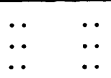 & $\begin{array}{r}7 \\
12 \\
3\end{array}$ & $\begin{array}{l}23 \\
17 \\
18\end{array}$ \\
\hline
\end{tabular}

ASSOCIATED FINDINGS DURING SOMNOLENT PHASE

C.S.F.-In five children the C.S.F. was examined within six weeks of irradiation, and though various abnormalities were found no consistent pattern emerged. The C.S.F. of two children showed mildly raised protein levels $(65 \mathrm{mg}$ and $67 \mathrm{mg} /$ $100 \mathrm{ml}$ respectively), and in a third 43 mononuclear cells $/ \mathrm{mm}^{3}$ were found. One child had an increase of C.S.F. protein from the third week of prophylaxis to a maximum value of $750 \mathrm{mg} /$ $100 \mathrm{ml}$ five weeks later, with a subsequent fall to normal values. Mononuclear cells were present on two occasions. She had no additional clinical abnormalities. The C.S.F. from the remaining child was normal.

E.E.G. Changes.-In five children E.E.G. was performed during the somnolent phase, and in three with severe symptoms it was repeated after full recovery. All initial tracings showed similar abnormalities, consisting of irregular, of ten rhythmic activity of intermediate slow components at 3-7 c/ sec over both hemispheres. When repeated after recovery similar but milder changes were seen, signifying considerable improvement. In every case these abnormalities were considered to be consistent with a diffuse cerebral disturbance affecting both hemispheres and without evidence of any focal cerebral lesion.

\section{Discussion}

There can be little doubt that this syndrome of somnolence occurring after C.N.S. prophylaxis is an acute transient cerebral disturbance, or encephalopathy, which is related to the cranial irradiation.

In 1929 Druckmann described an identical syndrome in 30 out of 1,100 children treated for ringworm of the scalp by irradiation with $150-\mathrm{kV} x$-rays, in which somnolence associated with anorexia, apathy, and headache occurred six to eight weeks after irradiation. Symptoms persisted for four to 14 days and resolved completely and spontaneously with no mental or physical sequelae up to four years later. Druckmann's report represents a very important precedent, for these children had no known intracranial abnormality but developed symptoms as a result of cerebral irradiation. He abolished the incidence of this syndrome by reducing the $x$-ray energy to $70 \mathrm{kV}$, thus limiting the cerebral dose received.

Rider (1963) described more severe neurological disturbances in three patients 10 weeks after radical high-dose radiotherapy for extracranial malignant disease. Similar transient cerebral disturbances in which drowsiness was a prominent feature were reported by Boldrey and Sheline (1966) in patients who had received high-dose radiotherapy for intracranial tumours, and were thought to represent a radiation reaction in the normal brain tissue adjacent to the neoplasm. Such postirradiation effects are difficult to distinguish from changes within the tumour or at the operative site in those who have undergone previous neurosurgery.

None of the children in our series had any clinical neurological abnormality before C.N.S. prophylaxis and all had normal C.S.F. cell, protein, sugar, and folate contents. It is probable that microscopic foci of leukaemic cells are present in the C.N.S. of a high proportion of children with acute lymphoblastic leukaemia when full remission is achieved, in view of the high incidence of C.N.S. relapse when C.N.S. prophylaxis is not given (Evans et al., 1970; Pinkel et al., 1971; West et al., 1972). Price and Johnson, (1973) have shown that these foci are in the arachnoid and not within the cerebral cortical tissue. It is unlikely, therefore, that any cerebral abnormality was present in our children before irradiation.

It is our view that this syndrome of somnolence represents a transient radiation-induced disturbance of myelination, and there is much indirect evidence to support this. Many workers have shown that radiation can inhibit myelin synthesis (Reynolds, 1946; Arnold et al., 1954; Innes and Carsten 1961; 
Rider, 1963; Schjeide et al., 1966), and demyelination after high-dose $x$-irradiation has been found in animals and man (Innes and Carstan 1961; Rider, 1963). The development of transient radiation myelopathy in some patients after cervical cord irradiation (Jones, 1964) is an important analogous syndrome. These patients may complain of an electric-shock-like sensation in the limbs and down the back on flexing the neck, eight to 12 weeks after irradiation of the neck including the cervical spinal cord ("Lhermitte's sign of electrical paraesthesiae"), which may persist for several months. Jones (1964) postulated that irradiation inhibits the synthesis of myelin by the oligodendroglia and that the latent period reflects an absence of effect on preformed myelin; the symptomatic phase reflects relative demyelination, with clinical recovery after increased myelin synthesis. This sequence of events is equally applicable to the cerebral syndrome. Clinicopathological verification of this concept within this dose range is lacking in man but there is experimental evidence in animals that myelin synthesis is suppressed by radiation.

The E.E.G. abnormalities during somnolence support the concept of a diffuse cerebral disturbance, with improvement noted after clinical recovery. E.E.G. studies before and at appropriate stages during treatment are still in progress and may help to clarify the significance of these abnormalities.

The development of this somnolence syndrome after prophylactic cranial irradiation has been noted by other workers using identical radiotherapeutic techniques both in Britain and elsewhere (Ward, 1973; Lampert, 1973). The remarkably high incidence of this syndrome reported here may be partly explained by our increased awareness of it, with specific inquiry for symptoms at the appropriate time. The unexpected development of somnolence in these children will inevitably cause much anxiety in parents and may lead to hospital admission and unnecessary investiation in an attempt to find a viral or bacterial cause for this encephalopathy. If additional clinical features are present appropriate investigations will be required. We now, therefore, advise all parents of this syn- drome before C.N.S. prophylaxis is begun, stressing its transient nature and complete recovery. This syndrome should be regarded as a minor and relatively unimportant complication of cranial irradiation in these children, just as the development of transient radiation myelopathy is regarded as an acceptable side effect of curative wide-field irradiation in Hodgkin's disease. It is a small price to pay for the proved efficacy of C.N.S. prophylaxis (Aur et al., 1972; Medical Research Council, 1973) in greatly reducing the incidence of meningeal leukaemia and improving the prognosis of acute lymphoblastic leukaemia.

We wish to thank Professor R. M. Hardisty and Dr. H. E. Kay for their advice and encouragement, Dr. A. Jones for helpful discussion, and Dr. G. Pampiglione for the E.E.G. assessments. We also acknowledge secretarial help from Miss $H$. Totman and Miss P. Kay-Smith.

\section{References}

Arnold, A., Bailey, P., and Harvey, R. A. (1954). Neurology (Minneapolis),

Aur, R. J. A., Simone, J. V., Hustu, H. O., and Verzosa, M. S. (1972). Cancer (Philadelphia), 29, 381.

Boldrey, E., and Sheline, G. (1966). Acta Radiologica, 5, 5.

Druckmann, A. (1929). Strahlentherapie, 33, 382

Evans, A. E., Gilbert, E., and Zandstra, R. (1970). Cancer (Philadelphia), 26, 404 .

Innes, J. R. M., and Carsten, A. (1961). Archives of Neurology, 4, 190.

Jones, A. (1964). British fournal of Radiology, 37, 727.

Lampert, F. (1973). Personal communication.

Medical Research Council (1973). British Medical fournal, $2,381$.

Pinkel, D., et al. (1971). Cancer (Philadelphia), 27, 247.

Price, R. A., and Johnson, W. W. (1973). Cancer (Philadelphia), In press.

Reynolds, L. (1946). American fournal of Roentgenology and Radiation Therapy, 55, 135.

Rider, W. D. (1963). Fournal of the Canadian Association of Radiologists, 14, 67.

Schjeide, O. A., Yamazaki, J., Haack, K., Ciminelli, E., and Clemente, C. D. (1966). Acta Radiologica, 5, 185

Ward, H. W. (1973). Personal communication.

West, R. J., Graham-Pole, J., Hardisty, R. M., and Pike, M. C. (1972). British Medical fournal, 3, 311.

\section{MEDICAL MEMORANDA}

\section{Haemolysis in Infectious Monnoucleosis: Inapparent Congenital Spherocytosis}

\section{J. J. TAYLOR}

British Medical fournal, 1973, 4, 525-526

Haemolysis in infectious mononucleosis sufficient to be an important feature of the clinical illness remains an infrequent occurrence. Usually the picture is of the autoimmune type, with spherocytosis, increased osmotic fragility, a positive result in the antiglobulin test, or the presence of cold agglu-

Hull Hospital Groups

J. J. TAYLOR, M.B., M.R.C.PATH., Consultant Clinical Haematologist (Present address: States Pathological Laboratory, The Parade, St. Helier, Jersey C.I.) tinins. Typically such haemolytic episodes are transitory, being followed by complete recovery within a few weeks (Dacie, 1963; Wintrobe, 1967). Three recent cases have been observed in which haemolysis during glandular fever did not conform to this pattern and investigation showed previously inapparent congenital spherocytosis.

\section{Case 1}

An 18-year-old woman developed malaise, fever, sore throat, and cervical adenopathy and a few days later became jaundiced. Haemoglobin was $10.8 \mathrm{~g} / 100 \mathrm{ml}$ and the W.B.C. $6,400 / \mathrm{mm}^{3}$ (neutrophils 1,900 , lymphocytes 4,300 , and monocytes $200 / \mathrm{mm}^{3}$ ). The blood film showed a number of atypical lymphoid cells compatible with those seen in infectious mononucleosis; rare spherocytes and $8 \%$ reticulocytes were present. Serum bilirubin was $4 \cdot 2 \mathrm{mg} / 100 \mathrm{ml}$. Results of direct antiglobulin tests were negative but the PaulBunnell test gave a titre of 320 . Osmotic fragility was greatly increased, confirming spherocytosis. Autohaemolysis at 24 hours was $5.4 \%$ without glucose, $3.1 \%$ with glucose, and $4.5 \%$ with adenosine triphosphate.

At that stage it became known that other members of the family had been investigated, and it was possible to construct a family tree showing her to have hereditary spherocytosis. Complete recovery followed without treatment in three weeks. 